\title{
Isolated Fournier's gangrene of the penis with penile autoamputation
}

\author{
Siddharth Pandey, Deepanshu Sharma, Ajay Aggarwal, Ashish Sharma
}

Department of Urology, King George's Medical University, Lucknow, Uttar Pradesh, India

Correspondence to Dr Siddharth Pandey, sid1420@gmail.com

Accepted 5 September 2018

\section{DESCRIPTION}

A 65 -year-old non-diabetic man presented to us with blackish discolouration of his penile shaft for 10 days (figures 1 and 2). He had undergone total thyroidectomy for follicular carcinoma of the thyroid gland 2 weeks previously. Intraoperatively, failed attempts were made to catheterise the patient. These attempts were traumatic, and a suprapubic catheter was hence placed. Following this, he developed inflammation and oedema on his penile shaft which then gradually started turning black for which he came to us. A diagnosis of isolated Fournier's gangrene of penis was made. Debridement was done, and the patient was advised regular dressings. During the initial debridement, the tunica albuginea and corpus cavernosa were not excised although the patient had slight gangrenous changes over the cavernosa. Later, gradually, a line of demarcation developed, and there was autoamputation of the involved shaft, 2 weeks after the initial debridement. The patient was advised a perineal urethrostomy. Before proceeding with surgery, a voiding cystourethrogram was done (figure 3) that showed that bulbar urethra was healthy but there was complete cut-off beyond it. During surgery, the autoamputation wound was freshened and secondarily closed (as in a total penectomy) and perineal urethrostomy was done (figure 4). The patient is doing well at 3-month follow-up.

Fournier's gangrene is a term now reserved for necrotising fasciitis of the genitals. Usually, it involves the male scrotum and may extend to the penis and abdominal wall. Isolated involvement of the penis is rare. The inciting factor for isolated Fournier's gangrene of penis may be periurethral abscess following trauma due to catheterisation or other instrumentation,

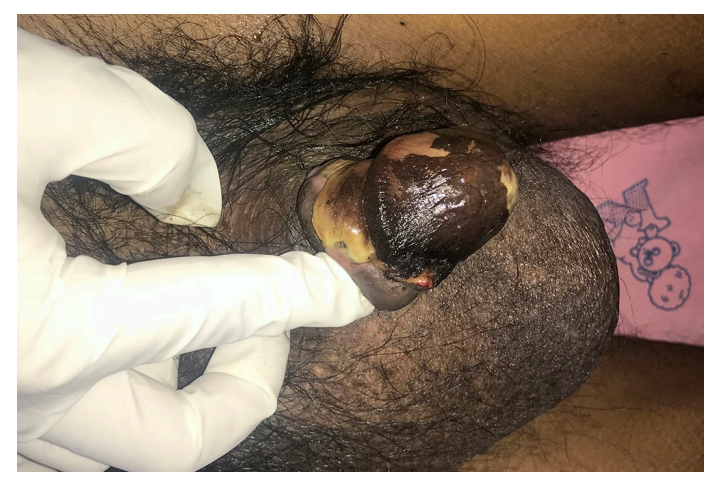

Figure 1 The penile gangrene on the dorsum.

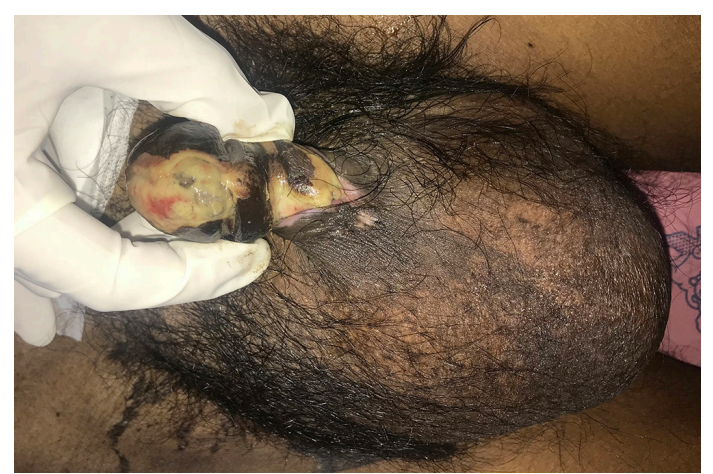

Figure 2 The penile gangrene on the ventral side.

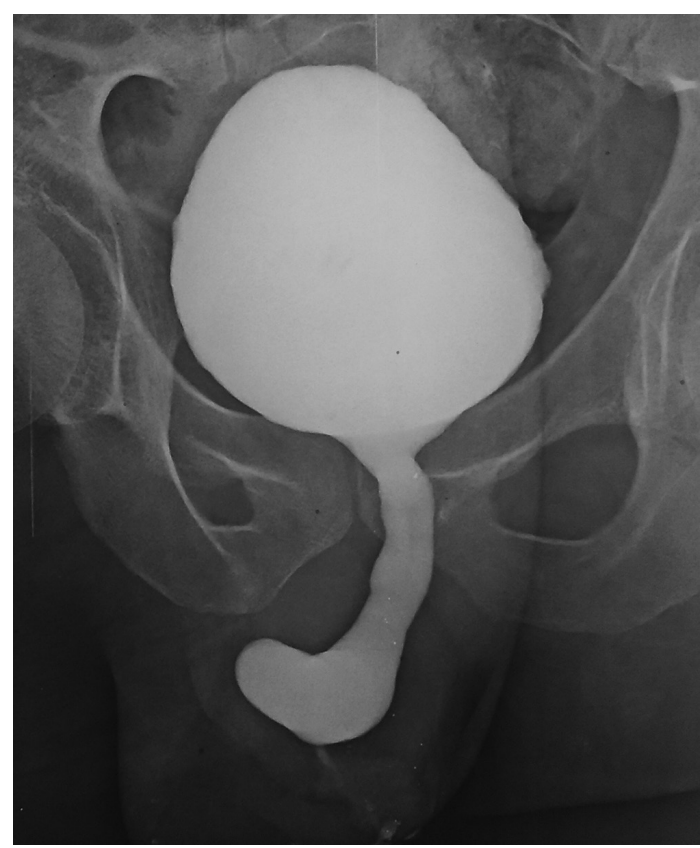

Figure 3 A voiding cystourethrogram showing healthy bulbar urethra and complete cut-off beyond it.

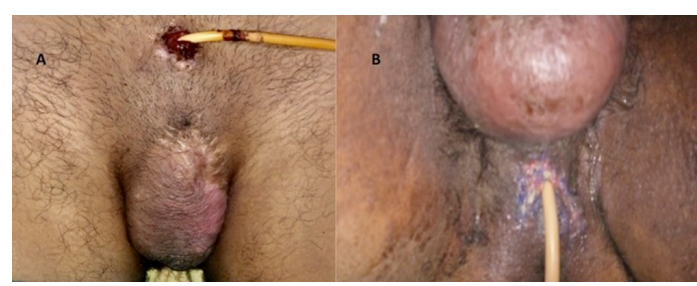

Figure 4 The healed wound of penile autoamputation after secondary closure of skin as in a total penectomy (A). The perineal urethrostomy (B).

penile injury during oral sex, anal intercourse and self injection of cocaine in the penis. ${ }^{12}$ Diabetes mellitus has been implicated as a risk 


\section{Learning points}

- Isolated penile gangrene is a rare entity that occurs due to trauma to the urethra by instrumentation/catheterisation followed by infection in an immune-compromised host.

- The treatment remains supportive initially with debridement and antibiotics. In severe cases, partial or total penectomy may be required along with a perineal urethrostomy.

- Usually in Fournier's gangrene of the penis, the corpus cavernosa and tunica albuginea are not involved by the infective process but there are cases in literature in which there has been penile autoamputation but in all these cases including ours there has been an underlying malignancy or chronic medical condition.

factor but our patient was non-diabetic. In our patient, there were attempts at placing a catheter that caused trauma leading to Fournier's gangrene. Postoperatively, there was decreased immunity, and the patient had a malignancy which might have contributed to him developing this condition, as immune-compromised status has been implicated as a causative factor. This might also have been the reason for progression to autoamputation of the penis. The other contributory factor was his advanced age. If the gangrene is not extensive then debridement followed by skin grafting could be an option, but when patients have extensive disease, partial or total penectomy with perineal urethrostomy remains a good option. ${ }^{3}$ Although Fournier's gangrene of the penis usually does not involve the cavernosa and tunica albuginea because their blood supply (internal pudendal artery) is different from the penile skin (external pudendal artery), still there are two previously reported cases with penile autoamputation. In both these cases, there was either an underlying malignancy (adenocarcinoma of the rectum) or a chronic medical condition (end stage renal disease). ${ }^{2}$ Ours would be the third such case in literature and also had an underlying malignancy (follicular carcinoma of thyroid).

Contributors SP conceived the case report. SP and AA were major contributors towards the writing of the manuscript. AS, SP and DS treated the patient and also interpreted the patient data. SP and AA were involved in the review. All authors read and approved the final manuscript.

Funding The authors have not declared a specific grant for this research from any funding agency in the public, commercial or not-for-profit sectors.

Competing interests None declared.

Patient consent Obtained.

Provenance and peer review Not commissioned; externally peer reviewed.

\section{REFERENCES}

1 Talwar A, Puri N, Singh M. Fournier's gangrene of the penis: a rare entity. J Cutan Aesthet Surg 2010:3:41.

2 Obi AO. Isolated Fournier's gangrene of the penis. Niger J Clin Pract 2016;19:426-30.

3 Singh V, Sinha RJ, Sankhwar SN. Penile gangrene: a devastating and lethal entity. Saudi J Kidney Dis Transp/ 2011;22:359.

Copyright 2018 BMJ Publishing Group. All rights reserved. For permission to reuse any of this content visit http://group.bmj.com/group/rights-licensing/permissions.

BMJ Case Report Fellows may re-use this article for personal use and teaching without any further permission.

Become a Fellow of BMJ Case Reports today and you can:

- Submit as many cases as you like

Enjoy fast sympathetic peer review and rapid publication of accepted articles

- Access all the published articles

- Re-use any of the published material for personal use and teaching without further permission

For information on Institutional Fellowships contact consortiasales@bmjgroup.com

Visit casereports.bmj.com for more articles like this and to become a Fellow 